\title{
Het Nader rapport bestuurlijke boetestelsels: een stap terug in duidelijkheid?
}

\section{Arnt Mein en Benny van der Vorm*}

In de loop der tijd hebben zich verschillende, op zichzelf staande sanctiestelsels ontwikkeld. Het meest in het oog springend is de opkomst van de bestuurlijke boete naast het strafrecht als klassiek sanctiestelsel. Echter, ook binnen het strafrecht wordt tegenwoordig het merendeel van de zaken buitengerechtelijk afgedaan door de politie, bijzondere opsporingsdiensten en het Openbaar Ministerie. Mede als gevolg hiervan is een breed scala aan overheidsorganen belast met het opleggen en tenuitvoerleggen van sancties: niet alleen de traditionele opsporingsdiensten en rijksinspecties, maar ook nieuwe marktmeesters en zelfs de burgemeester (Mein 2015, p. 22-28). Het bestaan van verschillende sanctiestelsels vraagt evenwel om een goede onderlinge afstemming tussen de instanties waaraan een rol is toebedeeld in de rechtshandhaving. Versplintering van de sanctietoepassing dient immers te worden vermeden. Zo is door critici wel gewezen op wildgroei binnen het sanctiestelsel en het ontstaan van verwarring over het toepasselijke regime (Hartmann 2005, p. 92 e.v.; Mevis 2005). In dit verband dient zich dan ook de vraag aan in hoeverre er nog sprake is van samenhang en evenwicht in de rechtshandhaving.

Dit vraagstuk speelt bij uitstek op het gebied van het punitieve bestuursrecht in relatie tot het strafrecht. Dit vormde dan ook de aanleiding tot een kritisch, ongevraagd advies van de Afdeling advisering van de Raad van State (hierna: Afdeling) over de verhouding tussen het bestuursrechtelijke en het strafrechtelijke sanctiestelsel. ${ }^{1}$ De Afdeling vraagt daarin aandacht voor de rechtsbescherming van de burger bij

* Mr. dr. A.G. Mein is lector bij de faculteit Maatschappij en Recht van de Hogeschool van Amsterdam. Mr. dr. drs. B. van der Vorm is universitair docent Straf(proces)recht en is verbonden aan het Willem Pompe Instituut en het Montaigne Centrum voor Rechtsstaat en Rechtspleging van de Universiteit Utrecht.

1 Analyse van enige verschillen in rechtsbescherming en rechtspositie van de justitiabele in het strafrecht en het bestuursrecht. Advies van 13 juli 2015, nr. W03.15.0138/II. Stcrt 2015, 30280. 
de keuze door de wetgever voor een sanctiestelsel omdat, anders dan bedoeld, tegenwoordig relatief hoge bestuurlijke boetes kunnen worden opgelegd voor zware vergrijpen. Dit advies dateert inmiddels van 2015. In het voorjaar van 2018 verscheen de langverwachte kabinetsreactie op dit advies, in de vorm van een nader rapport bestuurlijke boetestelsels. ${ }^{2}$ Het kabinet neemt in dit rapport een standpunt in over de verhouding tussen het punitieve bestuursrecht en het strafrecht. De vraag is echter of hiermee de gewenste samenhang en evenwicht wordt gerealiseerd.

In deze bijdrage geven wij commentaar op twee kernelementen uit het kabinetsstandpunt: het op elkaar afstemmen van de boetehoogtes in het bestuursrecht en het strafrecht en de onderbouwing van de keuze voor een sanctiestelsel. Wij werpen twee vragen op: in hoeverre is er werkelijk sprake van afstemming en op welke wijze dient de keuze tussen bestuursrecht en strafrecht te worden gewaardeerd in relatie tot het begrippenpaar 'instrumentaliteit' en 'moraliteit'? Om deze vragen te kunnen beantwoorden gaan wij eerst kort in op de hoofdlijnen van het kabinetsstandpunt, in relatie tot eerdergenoemd advies van de Afdeling. Daarna volgt het standpunt van het kabinet inzake de harmonisatie van de boetehoogtes. Vervolgens onderwerpen wij het door het kabinet voorgestane keuzecriterium aan een kritische analyse. Wij sluiten af met een korte conclusie.

\section{Het Nader rapport bestuurlijke boetestelsels op hoofdlijnen}

Het kabinet stelt in zijn reactie op het advies van de Afdeling voorop dat het huidige boetebestel over het algemeen adequaat functioneert. Met name de bestuurlijke boete voorziet in een blijvende behoefte en heeft zijn bestaansrecht ruimschoots bewezen (p. 5-6 en 24). Anders dan de Afdeling ziet het kabinet de gegroeide verschillen in rechtsbescherming binnen het strafrecht en het bestuursrecht niet als een wezenlijk probleem (p. 9). Het probleem zit vooral in de hoogte van die boete (Bröring \& Keulen 2016, p. 32-33), meer in het bijzonder de evenredigheid van de bestuurlijke boete in relatie tot de ernst van de overtreding en de omstandigheden van het geval. Die is in de juridische vakliteratuur en jurisprudentie veelvuldig bekritiseerd. ${ }^{3}$

2 Nader Rapport bestuurlijke boetestelsels, Stcrt. 2018, 31269.

3 Voor die literatuur en jurisprudentie zij verwezen naar het advies (o.a. p. 6-7). 
Het problematische karakter van de bestuurlijke boete houdt volgens het kabinet verband met drie samenhangende ontwikkelingen binnen het boetebestel (p. 16-23). Zo heeft, om te beginnen, de bestuurlijke boete een enorme vlucht genomen in het ordeningsrecht. Belangrijker was dat vervolgens steeds hogere bestuurlijke boetes konden worden opgelegd voor ernstiger overtredingen, bijvoorbeeld in het financieeleconomisch bestuursrecht (Mededingingswet, Wet op het financieel toezicht), maar ook in het sociale bestuursrecht (Participatiewet). Verder zijn het punitieve bestuursrecht en het strafrecht steeds meer naar elkaar toegegroeid, waardoor de onderlinge verschillen steeds geringer werden.

\section{Harmonisatie boetehoogtes}

Het kabinet signaleert vervolgens dat mede door deze ontwikkelingen het 'maatschappelijk en juridisch draagvlak' voor de bestuurlijke boete dreigt af te brokkelen. Dit zou vervolgens een negatieve weerslag kunnen hebben op de nalevingsbereidheid. Bijsturing is dan ook gewenst, aldus het kabinet. Die bijsturing heeft niet alleen betrekking op de hoogte van de bestuurlijke boete, mede in relatie tot die in het strafrecht, maar ook op verschillen in boetehoogtes binnen het bestuursrecht (p. 7 en 25). ${ }^{4}$ Uiteindelijk moet het boetebestel coherent en begrijpelijk zijn, zodat het overheidsoptreden als evenwichtig en rechtvaardig wordt ervaren (p. 8-9).

\section{Keuzecriterium boetestelsel}

Verder dan deze harmonisatie wil het kabinet niet gaan. Het brandt niet (opnieuw) zijn vingers aan het, aan eerdergenoemde verschillen ten grondslag liggende, probleem van afbakening tussen het strafrecht en het bestuursrecht. Volgens het kabinet is het namelijk niet mogelijk gebleken een onderscheidend criterium te vinden op grond waarvan bij het ontwerpen van wetgeving een keuze gemaakt kan worden voor

4 De maximumhoogte van de boete in het strafrecht bedraagt momenteel $€ 830.000$ of $10 \%$ van de jaaromzet in geval van een rechtspersoon, op basis van art. 23 Wetboek van Strafrecht (Sr). In het bestuursrecht kan de boete wel oplopen tot bijvoorbeeld $€ 5.000 .000$ (en $€ 10.000 .000$ in geval van recidive) of 10 tot $15 \%$ van de jaaromzet, bijvoorbeeld in geval van ernstige overtredingen begaan door grote financiële ondernemingen op basis van art. 1:81 en 1:82 van de Wet op het financieel toezicht (Wft). Binnen het bestuursrecht bestaan grote variaties wat betreft de maximumhoogte van een boete. Zo kan op basis van diezelfde Wft een boete worden opgelegd van $€ 10.000$ in geval van lichte overtredingen. 
het punitieve bestuursrecht of het strafrecht (p. 8). Die keuze moet voortaan overtuigender worden onderbouwd, waarbij kan worden geput uit alle denkbare, eerder geformuleerde indicatoren en criteria. Vooral moet worden beargumenteerd dat het gekozen sanctiestelsel efficiënt, effectief en evenredig is (p. 8-9).

\section{De onderlinge afstemming van de boetehoogtes}

Zoals gezegd acht het kabinet bijsturing wenselijk ten aanzien van de ontwikkeling van de hoogte van de bestuurlijke boete, mede in relatie tot het strafrecht. De eerder ontwikkelde Boetewijzer, bedoeld om meer eenheid te brengen in het boetebestel, heeft in het verleden het tij onvoldoende kunnen keren. ${ }^{5}$ Het kabinet wil de uniformiteit en de onderlinge afstemming op het gebied van de maximumhoogte van boetes dan ook nadrukkelijker stimuleren door te bewerkstelligen dat de wettelijke maximale boetehoogtes zich logischer tot elkaar gaan verhouden, zodat er meer eenheid en evenwicht in het boetebestel ontstaat (p. 25-26). In het bijzonder geldt dit voor het ordeningsrecht, waar zogenoemde duale handhaving mogelijk is (dat wil zeggen dat een overtreding bestuursrechtelijk en, onder omstandigheden, strafrechtelijk kan worden afgedaan). Volgens het kabinet is het in voorkomende gevallen niet uit te leggen dat de boete die de strafrechter dan kan opleggen, lager is dan die welke het bestuursorgaan kan opleggen.

\section{Maatregelen}

Het kabinet kondigt derhalve de volgende maatregelen aan (p. 26-28): ${ }^{6}$

1. Een voorstel tot wijziging van de Algemene wet bestuursrecht dat ertoe strekt dat bij de keuze voor de wettelijke maximumhoogte van een (nieuwe) bestuurlijke boete voortaan wordt aangesloten bij de strafrechtelijke boetecategorieën.

Het kabinet merkt hierbij wel meteen op dat dit met zich meebrengt dat eerst grondig moet worden nagegaan of de bestaande strafrechte-

5 Boetewijzer voor het bepalen van de maximumboete in wetgeving, Den Haag: ministerie van Veiligheid en Justitie 2014.

6 In deze bijdrage bespreken wij de belangrijkste maatregelen. 
lijke boetecategorieën niet moeten worden aangepast om aansluiting van de bestuurlijke boetes mogelijk te maken.

1. In het verlengde hiervan zullen bestaande bestuurlijke boetestelsels waarvan de maxima niet aansluiten op de strafrechtelijke boetecategorieën, door middel van wetswijziging worden aangepast.

Hier maakt het kabinet een volgend voorbehoud. Beargumenteerde uitzonderingen zijn mogelijk, indien daartoe een bijzondere rechtvaardiging bestaat.

2. De afstemming van wettelijke boetemaxima binnen het bestuursrecht zal worden geïntensiveerd door middel van de Aanwijzingen voor de regelgeving.

3. Een voorstel om in de Algemene wet bestuursrecht te verankeren dat waar duale handhaving mogelijk is, de maximale bestuurlijke boete voor overtreding van dezelfde norm niet hoger is dan die in het strafrecht.

Ook hier geldt dat wel eerst zal worden nagegaan of de bestaande strafrechtelijke boetecategorieën niet moeten worden aangepast om de beoogde afstemming te realiseren.

4. In het verlengde daarvan zullen bestaande duale stelsels worden aangepast door middel van wetswijziging. De bestuurlijke boete mag voor overtreding van dezelfde norm niet hoger liggen dan de strafrechtelijke boete.

Het kabinet tekent hierbij aan dat voor bestaande stelsels telkens een zorgvuldige afweging van geval tot geval zal worden gemaakt. Als ijkpunt dient daarbij de mate waarin de onderlinge verhoudingen alsmede die tot vergelijkbare boetes logisch te verantwoorden zijn. Als praktische keerzijde van deze formele maatregelen zullen de desbetreffende bestuursorganen en het Openbaar Ministerie hun boetebeleid respectievelijk rekwireerbeleid zo veel mogelijk op elkaar afstemmen.

Harmonisatie, maar dan wel naar boven...

Op het eerste gezicht lijkt er sprake te zijn van de door het kabinet aangekondigde bijsturing. Wat betreft de hoogte van de bestuurlijke 
boete moet voortaan aansluiting worden gezocht bij de strafrechtelijke boetemaxima. Overigens valt op dat daarvoor een principiële onderbouwing ontbreekt: waarom wordt het strafrecht als referentiekader genomen? Niettemin juichen wij dit streven naar harmonisatie toe. Immers, de trend naar steeds hogere boetes in het (financieel-economisch) bestuursrecht dient wat ons betreft te worden omgebogen. Die boetes zijn vooral symboolpolitiek, ingegeven door een sterk geloof in de afschrikkingsgedachte en een beeld van calculerende overtreders. De praktijk wijst anders uit; daarnaast blijkt dit type boete sterk te worden gematigd door toezichthouder en rechter (Mein 2017). In de kern is dit ook de boodschap van het advies van de Afdeling: wetgever: bezin u op de torenhoge boetes in het bestuursrecht.

Echter, bij nadere beschouwing rijst de vraag in hoeverre er nu werkelijk sprake is van bijsturing. De maatregelen zijn namelijk erg omzichtig en vrijblijvend geformuleerd. Eerst zal bezien worden in hoeverre het strafrechtelijke boetestelsel aangepast (lees: verhoogd) moet worden om de beoogde aansluiting mogelijk te maken (p. 26). Zo zou het kunnen zijn dat de voorgestelde harmonisatie leidt tot een opwaartse bijstelling van de boetemaxima uit het Wetboek van Strafrecht.

Immers, de strafrechtelijke boetemaxima zouden wel eens te laag kunnen zijn om aansluiting vanuit het bestuursrecht mogelijk te maken.

Het beeld is dat nogal wat bestuursrechtelijke boetemaxima aanzienlijk hoger liggen en het is nog maar de vraag of het gelet op Europese verdragsverplichtingen mogelijk is en beleidsmatig wenselijk wordt geacht die naar beneden bij te stellen, gelet op de vermeende afschrikkende werking. Wat schieten we hier dan mee op in het licht van het advies van de Afdeling?

In het verlengde hiervan is ook de beoogde afstemming van de hoogte van de bestuurlijke boete op de strafrechtelijke boete binnen duale stelsels even vrijblijvend en vaag geformuleerd. Ook hier zal eerst bezien worden of de strafrechtelijke boetemaxima bijgesteld (lees: verhoogd) dienen te worden om aansluiting mogelijk te maken (p. 27). Via dezelfde u-bocht kunnen er hogere boetes uitkomen. Hetzelfde beeld geldt voor de afstemming van de boetemaxima binnen het bestuursrecht. Brengt opname van de wens tot afstemming in de Aanwijzingen voor de Regelgeving werkelijk verandering in de huidige situatie? Zullen de vakdepartementen hier niet hun eigen gang blijven gaan? Hoe denkt het ministerie van Justitie en Veiligheid op dit punt de door de Afdeling de gewenste regie te voeren? 


\section{De keuze tussen bestuursrecht en strafrecht}

De Afdeling is in haar advies kritisch over de begrippen 'open context' en 'besloten context' als tot nu geldend keuzecriterium. Ook in de literatuur is dit criterium bekritiseerd, omdat het onvoldoende onderscheidend zou zijn (Hartmann 2011, p. 40). Met betrekking tot dit keuzecriterium neemt de al dan niet aanwezige rechtsbetrekking tussen de burger en de overheid een belangrijke plaats in. Indien tussen de burger en de overheid een specifieke rechtsbetrekking bestaat, zoals een vergunningplicht, dan is sprake van een 'besloten context' en is de keuze voor het bestuursrecht geïndiceerd. Ontbreekt een rechtsbetrekking en heeft de regelgeving betrekking op iedereen, dan ligt de keuze voor het strafrecht in de rede. Het is het commentaar van de Afdeling geweest dat ertoe heeft geleid dat het kabinet zich opnieuw over de vraag de naar de werking van de 'besloten context' en 'open context' heeft gebogen. In het nader rapport wordt aangegeven dat het commentaar in de ogen van het kabinet begrijpelijk is:

'Weliswaar zijn er bepaalde overtredingen waarvoor het op grond van het huidige beleid op voorhand glashelder is dat daarop alleen een strafrechtelijke reactie aan de orde kan zijn. Denk bijvoorbeeld aan het feiten waarbij sprake is van een ernstige inbreuk op de lichamelijke integriteit. Omgekeerd geldt dat er lichte overtredingen zijn waarbij van meet af aan duidelijk is dat met een bestuursrechtelijke sanctie kan worden volstaan. Maar juist voor die overtredingen waarbij discussie mogelijk is over de vraag welk type handhaving gekozen zou moeten worden ("grijs gebied"), geeft het bestaande beleid niet de gewenste sturing en doorslag.' (p. 8)

Het kabinet geeft onomwonden aan dat het ten aanzien van de keuze tussen bestuursrecht en strafrecht de 'open context' en 'besloten context' niet meer als uitgangspunt neemt. Betekent dit dat het kabinet een nieuw criterium heeft ontwikkeld? Het antwoord op deze vraag luidt ontkennend. Het kabinet constateert dat er geen nieuw, algemeen geldend en voldoende onderscheidend criterium is gevonden op grond waarvan een keuze tussen het bestuursrecht en het strafrecht in het grijze gebied kan worden gemaakt. Daarom neemt het kabinet het standpunt in dat alle reeds geformuleerde en bekende (contra-)indicatoren en criteria uit de bestaande nota's moeten worden gebruikt en beoordeeld. Waar Bröring deze indicatoren heeft aan- 
geduid als 'achterhaald', zijn deze nu weer springlevend (Bröring 2017, p. 318). In dit verband kunnen wederom de 'besloten context' en 'open context' worden gebruikt (p. 8). In de motivering van de keuze tussen bestuursrecht en strafrecht moet worden aangegeven waarom deze keuze optimaal bij zal dragen aan de bevordering van de naleving (p. 13). Ten aanzien van de keuze tussen bestuursrecht en strafrecht in het grijze gebied is de vraag naar optimale naleving naar het oordeel van het kabinet leidend. Het kabinet wijst op de volgende factoren op grond waarvan de optimale naleving kan worden gemotiveerd:

1. de feitelijke pakkans;

2. de aard van de sanctie;

3. de zwaarte van de sanctie;

4. het generaal en het speciaal preventieve effect;

5. de financiële en organisatorische implicaties die deze factoren met zich meebrengen;

6. de vraag in hoeverre de oplegde sanctie daadwerkelijk kan worden geïnd.

Er dient expliciet aandacht besteed te worden aan de samenhang en de logica van het handhavingsstelsel als geheel (p. 14). Wat betreft de keuze voor het bestuursrecht wijst het kabinet op de volgende factoren: organisatorische randvoorwaarden, de aanwezigheid van veelvoorkomende en/of betrekkelijk lichte overtredingen die eenvoudig zijn vast te stellen of waarbij in de praktijk niet wordt verwacht dat een rechterlijk oordeel wordt ingeroepen. Ook indien een bestuursorgaan beschikt over specifieke expertise is dat een indicatie voor het bestuursrecht (p. 14). Het strafrecht komt volgens het kabinet in aanmerking indien sprake is van gedragingen die naar hun aard behoren tot de ernstigste normschendingen, indien een bepaalde overtreding complex is of een bepaalde type (strafrechtelijk) onderzoek vergt, en in geval van noodzaak tot internationale samenwerking of rechtshulp. Ook is strafrechtelijke handhaving nodig indien een internationale verplichting bestaat tot een strafbaarstelling in het strafrecht (p. 15). Het kabinet heeft aangekondigd om in het IAK een handzaam overzicht te maken van alle relevante factoren en (contra-)indicatoren (p. 16). 


\section{Instrumentaliteit of moraliteit?}

In zijn afscheidsrede in 2014 heeft Rogier erop gewezen dat het kabinet zich bij de keuze tussen bestuursrecht en strafrecht vooral laat leiden door een instrumentele zienswijze. Hiermee bedoelt Rogier dat het recht wordt opgevat als een middel dat de overheid ten dienste staat om zo doeltreffend en doelmatig mogelijk ongewenst gedrag te bestrijden (Rogier 2014, p. 15). In de keuze tussen bestuursrecht en strafrecht vraagt hij meer aandacht voor het keuzecriterium van de ernstige gedraging, hetgeen hij vangt onder de term 'moraliteit'. In de opvatting van Rogier is 'moraliteit' het ongewenste gedrag waarover een ethisch waardeoordeel wordt geveld (Rogier 2014, p. 16). Indien sprake is van ernstige gedragingen ligt de voorrang bij de strafrechtelijke handhaving en niet bij het bestuursrecht. Weliswaar kan het bestuur in de zin van voorkoming een belangrijke bijdrage leveren aan de bestrijding van onrecht, maar het Openbaar Ministerie zou bij ernstige gedragingen 'meer zijn tanden moeten laten zien' en het optreden niet moeten overlaten aan het bestuur (Rogier 2014, p. 33). Hoe valt het standpunt van het kabinet te plaatsen in de termen 'instrumentaliteit' en 'moraliteit'? Het uitgangspunt van het kabinet is gelegen in de motivering waarom de keuze voor bestuursrecht of strafrecht optimaal zal bijdragen aan de bevordering van de naleving ( $p$. 13). Dit is ontegenzeggelijk een instrumenteel uitgangspunt. Door combinatie van alle criteria heeft het kabinet echter eveneens oog voor de ernst van de gedraging: indien sprake is van de ernstigste normschendingen, ligt de keuze voor het strafrecht in de rede. Het standpunt van het kabinet is dus aan te merken als instrumenteel, waarbij echter ook aandacht wordt gevraagd voor moraliteit. De zoektocht van het kabinet naar een algemeen criterium in de keuze tussen beide handhavingsstelsels is op niets uitgelopen. Nieuwe criteria worden door het kabinet niet genoemd. Hoe een en ander in de praktijk zal verlopen is onduidelijk, maar dat een instrumentele benadering voorop staat, is geen punt van discussie.

\section{Een principiële keuze: de ernstige gedraging}

In hoeverre bevordert het standpunt van het kabinet duidelijkheid over de keuze tussen bestuursrecht en strafrecht? Is sprake van een bepaalde hiërarchie in de criteria? Hoe moet worden omgegaan met 
criteria die onderling strijdig zijn? Is cherry picking mogelijk? Dergelijke vragen komen op indien alle criteria kunnen worden gebruikt in de keuze tussen bestuursrecht en strafrecht. In navolging van Rogier bepleiten wij een principieel standpunt. Indien sprake is van een ernstige gedraging dient te worden gekozen voor het strafrecht. De keerzijde hiervan is dat kan worden gekozen voor het bestuursrecht als het geen ernstige gedraging betreft. Wanneer is nu sprake van een ernstige gedraging? In dit verband kan aansluiting worden gezocht bij de mogelijkheid om een strafbeschikking uit te vaardigen. Er is sprake van een ernstige gedraging indien de mogelijkheid bestaat (of zou moeten bestaan) om een gevangenisstraf van meer dan zes jaren op te kunnen leggen (Van der Vorm 2017a). Met andere woorden: is de gedraging zó ernstig dat deze niet door het bestuur kan worden afgedaan? Als sprake is van dergelijke gedragingen, ligt het strafrecht voor de hand (Van der Vorm 2017b). In de andere gevallen, waarin afdoening buiten de rechter mogelijk zou moeten zijn, kan het bestuursrecht zijn dienst bewijzen. Naar onze mening is dit een helder en goed hanteerbaar criterium, waarbij de invloed van het door het kabinet bestempelde 'grijze gebied' zich minder laat voelen.

In tegenstelling tot het kabinet maken wij een principiële keuze voor de ernst van de gedraging (moraliteit). Zoals reeds is aangegeven is het uitgangspunt van het kabinet 'instrumentaliteit'. In principe is een dergelijke instrumentele visie niet problematisch, maar naar onze mening leidt de toepassing van alle reeds ontwikkelde criteria tot onduidelijkheid, waar duidelijkheid nu juist is beoogd. Zo biedt het bijvoorbeeld betere aanknopingspunten voor de (moeizame) verdeling en afstemming van zaken in het overleg tussen de vele bij de rechtshandhaving betrokken partijen (bijvoorbeeld het tripartiete overleg tussen het Openbaar Ministerie, de FIOD/ECD en de financiele toezichthouders).

\section{Conclusie}

Naar aanleiding van het ongevraagde advies van de Afdeling uit 2015 over de verhouding tussen het bestuursrechtelijke en het strafrechtelijke sanctiestelsel is in het voorjaar van 2018 de reactie van het kabinet naar buiten gekomen, het Nader Rapport bestuurlijke boetestelsels. In deze bijdrage zijn twee belangrijke aspecten uit dit rapport 
besproken, namelijk de onderlinge afstemming van de boetehoogtes en de keuze tussen bestuursrecht en strafrecht.

Het kabinet is voornemens om wat betreft de hoogte van de bestuurlijke boete voortaan aansluiting te zoeken bij de strafrechtelijke boetemaxima in artikel 23 Wetboek van Strafrecht. Een dergelijke poging tot harmonisatie juichen wij op zichzelf genomen toe, maar wij plaatsen er wel de nodige kanttekeningen bij. De vraag is in hoeverre er nu werkelijk sprake is van bijsturing. De maatregelen zijn namelijk erg omzichtig en vrijblijvend geformuleerd. Deze vrijblijvendheid heeft tot gevolg dat nog steeds torenhoge boetes mogelijk zijn, terwijl de kritiek van de Afdeling nu juist was gericht op die hoogte.

Met betrekking tot de zoektocht naar een algemeen criterium voor de keuze tussen bestuursrecht en strafrecht blijkt dat het kabinet deze niet heeft gevonden. Het standpunt van het kabinet is sterk instrumenteel gekleurd, waarbij het uitgangspunt is dat de keuze moet leiden tot optimale rechtshandhaving. Het kabinet erkent ook dat het strafrecht moet worden ingezet ten aanzien van de ernstigste gedragingen. Voorts neemt het kabinet geen afscheid van de criteria 'besloten context' en 'gesloten context'. Wij constateren dan ook dat het kabinet geen echte keuze maakt, want voortaan kunnen alle reeds ontwikkelde indicatoren worden gebruikt. Naar onze mening leidt dit niet tot de gewenste duidelijkheid. Het criterium van de ernstige gedraging biedt naar onze mening de mogelijkheid om heldere keuzes te maken. Indien sprake is van een ernstige gedraging (de gedraging mag niet door het Openbaar Ministerie worden afgedaan door middel van het uitvaardigen van een strafbeschikking), dient te worden gekozen voor het strafrecht. Als geen sprake is van een ernstige gedraging zou deze gedraging bestuursrechtelijk kunnen worden afgedaan.

Hoewel het kabinet met het Nader Rapport bestuurlijke boetestelsels duidelijkheid heeft beogen te scheppen, is het de vraag in hoeverre het ook daadwerkelijk tot duidelijkheid zal gaan leiden. Naar onze mening wordt het onderscheid tussen bestuursrecht en strafrecht er met dit nadere rapport (helaas) niet duidelijker op. 


\section{Literatuur}

\section{Bröring 2017}

H.E. Bröring, 'Keuze voor een sanctiestelsel: bestuurlijke boete of bestuurlijke strafbeschikking?', RegelMaat 2017, afl. 5, p. 317-335.

\section{Bröring \& Keulen 2016}

H.E. Bröring \& B.F. Keulen, Bestraffende sancties in het strafrecht en het bestuursrecht, Zutphen: Uitgeverij Paris 2016.

\section{Hartmann 2015}

A.R. Hartmann, 'Strafbeschikking en bestuurlijke boete: wildgroei in de handhaving?', JV2005, afl. 6, p. 84-96.

\section{Hartmann 2011}

A.R. Hartmann, Over de grenzen van de dogmatiek en into fuzzy law (oratie Rotterdam), Apeldoorn/Antwerpen: Maklu 2011.

\section{Mein 2015}

A.G. Mein, De boete uit balans. Het gebruik van de bestuurlijke boete in de praktijk van het financieel toezicht (diss. Rotterdam), Den Haag: Boom Lemma uitgevers 2015.

\section{Mein 2017}

A.G. Mein, 'Symboolpolitiek met hoge boetes in het kader van het financieel toezicht', in: R. Staring, R. van Swaaningen \& K. van Wingerde (red.), Over de muren van stilzwijgen, Den Haag: Boom Criminologie 2017, p. 271-283.

\section{Mevis 2005}

P.A.M. Mevis, 'Bestuurlijke boete in Absurdistan', Ars Aequi 2005, afl. $7 / 8$, p. 580-587.

\section{Rogier 2014}

L.J.J. Rogier, Bestuursrecht of strafrecht: instrumentaliteit of moraliteit? (Afscheidsrede Rotterdam), Den Haag: Boom Juridische uitgevers 2014.

\section{Van der Vorm 2017a}

B. van der Vorm, 'De keuze tussen strafrechtelijke en bestuursrechtelijke sanctionering en het criterium van de ernstige gedraging', PROCES 2017, afl. 4, p. 267-280.

\section{Van der Vorm 2017b}

B. van der Vorm, 'Bespiegelingen over de keuze tussen bestuursrecht en strafrecht', RegelMaat 2017, afl. 5, p. 336-348. 